A Catalyst-for-Change Approach to Evaluation Capacity Building 


\begin{abstract}
Evaluation capacity building (ECB) has become a popular approach for helping communitybased organizations (CBO) to meet their funders' demands for accountability. This case study reports the ECB process with one staff member using a catalyst-for-change approach. We analyzed the role of the catalyst in diffusing evaluation knowledge and skills and in promoting evaluation mainstreaming and use within the $\mathrm{CBO}$; and the outcomes achieved as a result of the catalyst's role in the process of building evaluation capacity. Implications based on the study findings are discussed.
\end{abstract}

Keywords: evaluation capacity building, catalyst approach, logic models, community-based organization 


\section{A Catalyst-for-Change Approach to Evaluation Capacity Building}

In the U.S., evaluation capacity building (ECB) has become a popular approach for helping community-based organizations (CBOs) to meet their funders’ demands for accountability (Carman, 2007; Preskill \& Boyle, 2008). However, organizations’ lack of resources, staff time, and funding (Connolly \& York, 2002) often negatively affect the process of implementing ECB efforts. To address the limitations organizations face in engaging in ECB efforts, we adopted a process of building evaluation capacity with one staff member, who, in turn, acted as a catalyst by transferring evaluation capacity to other members of her organization. In this article, we report our experiences using this catalyst approach in one CBO. First, we describe the ECB process with the staff member. Second, we examine the role of the catalyst as a change agent within the organization. Third and finally, we examine the outcomes achieved as a result of the catalyst's role in the diffusion of the ECB process.

\section{Literature Review}

Preskill and Boyle (2008) asserted that ECB "has become a hot topic of conversation, activity and study” (p. 443). During the last decade, evaluators have advocated for ECB as a strategy for helping organizations to meet increasing accountability requirements (Baizerman, Compton, \& Stockdill, 2002; Carman \& Fredericks, 2008; Compton, Glover-Kudon, Smith, \& Avery, 2002; Huffman, Thomas, Lawrenz, 2008; King, 2002; Milstein, Chapel, Wetterhall, \& Cotton, 2002; Stevenson, Florin, Mills, \& Andrade, 2002; Stockdill, Baizerman \& Compton, 2002). Stockdill et al. (2002) defined ECB as efforts to develop and sustain practices within organizations that make use of evaluation processes and practices routine. The goal of ECB is typically for staff within the target organization to regularly and effectively document the implementation and impact of their programs as a result of increases in evaluation capacity 
(Gibbs, Napp, Jolly, Westover, \& Uhl, 2002; King, 2002; Mackay, 2002; Milstein et al., 2002;

Preskill \& Boyle, 2008; Taut, 2007).

Within the study of ECB efforts, scholars have called for additional research that describes both the process of building evaluation capacity and the outcomes of such efforts (Baizerman, et al., 2002; Huffman, et al., 2008; Preskill \& Boyle, 2008). In terms of processes, many approaches and strategies are reported in the literature. To build evaluation capacity, many evaluators suggest the use of trainings, technical assistance and coaching/mentoring (Preskill \& Boyle, 2008) and immersion approaches in which targets of ECB efforts are actively involved in evaluation activities (Arnold, 2006; Huffman et al., 2008). When evaluation is perceived as a process that is likely to improve programs and increase the probability of obtaining funding, organizations are more likely to engage in and sustain evaluation activities (Compton, Baizerman, Preskill, Rieker, \& Miner, 2001). Further, organizations with evaluation capacity are more likely to use evaluation practices in routine operations as well as use evaluation results to inform decision making and program improvement (Carman, 2007).

In terms of ECB outcomes, scholars have noted outcomes at individual and organizational levels (e.g., Cousins, Goh, Eliott \& Aubry, 2008; Naccarella, Pirkis, Kohn, Morley, Burgess, \& Blashki, 2007; Suarez-Balcazar, et al., 2010). At the individual level, ECB studies have supported the examination of cognitive, behavioral, and affective outcomes (see Arnold, 2006; Taut, 2007; Trevisan, 2002; Valery \& Shakir, 2005). Taut (2007) defines cognitive outcomes as including increasing evaluation knowledge and evaluative thinking that is incorporated into everyday professional practice. Behavioral outcomes include improving skills to integrate evaluation into everyday practice. Affective outcomes are positive changes in attitudes towards evaluation, increasing ownership regarding evaluation, and increasing 
motivation to engage in evaluation. At the organizational level, ECB studies have provided support for examining the ongoing use and mainstreaming of evaluation practices (see Cousins et al., 2008; Stockdill et al., 2002; Suarez-Balcazar et al., 2010).

Organizations may struggle to commit to ECB processes. Past ECB studies have focused on the importance of an evaluator training several staff from the same CBO or the same system (e.g., schools) to build their evaluation capacity with the expectation that these staff will diffuse their evaluation skills within their organization (see Baizerman, et al., 2002; Compton, et al., 2002; King, 2002; Mackay, 2002; Milstein et al., 2002). To engage in this type of ECB process, CBOs must allocate significant resources in terms of the number of staff who participate and the time they spend on evaluation (Naccarella et al., 2007). However, the reality is that CBOs often have limited staff available to work with an evaluator to develop their evaluation capacity (Carman, 2007; Connolly \& York, 2002). This challenge highlights the importance of focusing ECB efforts on a single staff person, when necessary, and using a catalyst approach to support the diffusion of evaluation activities within the organization.

Herein we describe a catalyst-for-change approach to ECB. To build on the existing ECB literature, this case study focuses on the processes and outcomes of building evaluation capacity with one key leader who served as a catalyst for change within a CBO. A catalyst approach in ECB is not new. Taut (2007) used the concept of catalyst in the context of self-evaluations among evaluators working on ECB. Here, the concept of catalyst refers to an individual in a leadership position who facilitates significant change in: (1) other staff members' evaluation knowledge and skills and (2) the organization's mainstreaming and use of evaluation practices (Suarez-Balcazar et al., 2010). In this approach, the role of a key leader as the catalyst is critical. A leader has the power to influence the use of resources to change the organization's evaluation 
practices and to provide the needed infrastructure for program evaluation to become central to the organization's routine activities (Hoole \& Patterson, 2008).

\section{Case Study}

\section{Context and Background}

The authors represent a partnership between a CBO serving people with intellectual disabilities (ID) and the Center for Capacity Building on Minorities with Disabilities Research (CCBMDR) at the University of Illinois at Chicago with the purpose of facilitating ECB. Part of the mission of the CCBMDR was to create evaluation capacity within CBOs, centers for independent living, and vocational rehabilitation offices so they could assess the impact of their programs in order to better serve and meet the needs of people with disabilities from multiple cultural backgrounds. The CBO, located in a Latino neighborhood in Chicago, provided a wide array of services_-from early intervention to adult programs—-to people with ID. In this case study, the ECB focused on the CBO’s employment program coordinator. The program coordinator became a partner of the university team and the target catalyst of ECB process.

One of the goals of the employment program was to provide supports to adults with ID so that they could obtain and maintain employment. The employment program received funding from several sources, including the state government and United Way. To receive state funding for the services provided, the employment program assisted program participants in securing employment that lasted for at least 90 days. United Way funding was contingent on the availability of funds and on the development of a program logic model and an outcomes measurement system.

At the beginning of the partnership, the employment program was providing services to 30 adults with ID and employed four job coaches who worked on-site with the program 
participants, one job-coach supervisor, six counselors, and a program coordinator. The program coordinator was responsible for all of the program evaluation activities.

\section{The Evaluation Capacity Building Process}

The first purpose of this article is to describe the ECB process at this organization. In this case study, we use Preskill and Boyle’s (2008) stages of planning, designing, and implementing ECB efforts to structure the report of the process. What follows is a description of the planning, designing, and implementation of the ECB process (see Table 1 for a summary of the ECB process).

Planning and designing the ECB process. To launch the step of planning and designing the ECB process, we first engaged in an assessment of the program's readiness for ECB.

Assessing program readiness for $\mathbf{E C B}$. ECB proponents have noted the need to conduct an assessment of an organization's readiness to engage in a process that is designed to build evaluation capacity (Taut, 2007). In order to examine organizational readiness, evaluators have suggested conducting interviews, observing competencies, reviewing processes and practices at the organization, and reviewing evaluation reports and other documents produced by the organization. Here, the readiness assessment involved (1) partners sharing and clarifying motivations, assumptions, and expectations for the evaluation and (2) partners sharing knowledge about the program. After conducting the readiness assessment, we discussed the assessment findings. This discussion was critical in planning and designing the ECB process.

Sharing and clarifying motivations, assumptions and expectations. As part of the readiness assessment, we shared and clarified our motivations, assumptions, and expectations related to evaluation (Compton et al. 2001; Preskill \& Boyle, 2008). To do so, the university partners (the first three authors of this article) held several brainstorming sessions with the 
program coordinator (the fourth author) and her supervisor. These meetings helped to clarify the organization’s and program coordinator's needs for building evaluation capacity; their assumptions, knowledge, skills, and motivations for conducting evaluations and their expected goals for the ECB process.

The brainstorming sessions revealed much about the employment program. Notably, the program coordinator had no evaluation training aside from attending two United Way training sessions. Although senior managers in the organization were asking the program coordinator to evaluate the employment program, she felt she lacked the knowledge and skills to conduct an evaluation. She reported that she wanted to engage in the ECB process, not only because senior managers and funders required her to do so, but also because she considered the ECB process an opportunity to build her evaluation competencies and add to her resume.

Sharing knowledge about the program. A second critical aspect of the readiness assessment involved learning more about the program itself. To do this, we agreed to review annual and monthly reports, information databases that the program coordinator managed, and evaluation forms used by frontline staff. The university partners also conducted an open-ended interview with the program coordinator to learn about the program’s history, goals, and objectives.

The assessment of documents and the interview with the program coordinator revealed several challenges that the program coordinator was having in evaluating the employment program. For example, although the program coordinator and her staff collected data on participants' satisfaction with the program, they only included these data in annual reports to funders and did not use it internally for evaluation purposes, such as program improvement. Further, frontline staff, including job counselors and job coaches, were documenting and 
reporting the amount of support provided to adults with ID, the number of employment training sessions attended by participants, and other outputs for billing purposes only. Frontline staff, however, did not track outcomes. Moreover, the employment program lacked an integrated documentation and reporting system, which resulted in the use of multiple forms with duplicated information. These practices led to the program coordinator's storing away reports once the program staff compiled the information and they sent it to funders. The evaluation information that program staff collected also revealed little about how program activities might influence program outcomes. In summary, the employment program staff collected data within the employment program and used them for reporting and billing purposes to account to external funders. Data, however, were not adequate and program staff did not used them internally for evaluation purposes.

Planning and designing the ECB process. Based on the results of the readiness assessment, we were able to plan and design the ECB process. We agreed to work on enabling the program coordinator to build her skills on how to develop a comprehensive and unified system for evaluating the employment program. Specifically, we agreed on the following two ECB objectives: (1) develop a logic model as a tool for planning and implementing an evaluation and (2) conduct an outcomes evaluation of the employment program. In this way, we designed the ECB process to address the accountability needs of the program, the problems that we identified with the documentation system and the interests of the program coordinator.

The ECB process and activities. The ECB literature describes multiple approaches and strategies for engaging in ECB. For this case study, we used a combination of the collaborative immersion approach suggested by Huffman et al. (2008); strategies from Preskill and Boyle’s (2008) ECB model, including the teaching and learning strategies of brainstorming meetings, 
trainings, technical assistance and coaching/mentoring; and Merriam, Caffarella, and Baumgartner's (2007) constructivist adult learning theory. According to Huffman et al., the collaborative immersion approach involves partners working together throughout the phases of conducting an evaluation so that the target of the ECB effort develops the knowledge and skills that are necessary to conduct an evaluation. We used the collaborative immersion approach to provide the program coordinator with the opportunity to shape the process and provide ongoing input into the strategies that we used. As a foundation for our approach, we relied on the constructivist (see Merriam et al., 2007) adult learning theory, which emphasizes learners constructing new knowledge based on previous and current experiences. This theory posits that creating new knowledge is an active process of constructing meaning and making sense of experiences that occur through dialogue, collaboration, and immersion.

To document the ECB process and its outcomes, the university partners used direct observation, document reviews, activity logs, and entry and exit interviews with the program coordinator. The university partners recorded their observations throughout and at the end of the partnership on activity logs that ordered their and the program coordinator's activities chronologically, including the type of activity, number of people involved, the program coordinator's or other staff's comments and reactions, and the lessons learned.

Developing a program logic model. We agreed that the first step in the ECB process was to focus on building skills in developing a logic model as a tool for planning and implementing an evaluation of the employment program. Some scholars have suggested using a logic model approach to guide the teaching of evaluation skills (Connolly \& York, 2002; Kapucu, Augustin, \& Krause, 2007). Logic models are one of the predominant design approaches for evaluation and one of the core components of the United Way approach to measuring program outcomes 
(Behrens \& Kelly, 2008). Although several approaches to developing a logic model appear in the literature, most CBOs are familiar with the United Way model, in part because they obtain funding from United Way and their staff participate in United Way trainings (Gugiu \& Rodriguez-Campos, 2007). The United Way logic model includes the following components: inputs (resources), activities (actions to affect change), outputs (products of the activities), and short-term, intermediate, and long-term outcomes (intended benefits for program users) (United Way of America, 1996).

To develop the employment program logic model, the university partners first conducted a full one-day workshop for program staff on the development of logic models as an evaluation tool. Although the focus of the collaboration was on building the evaluation skills of the program coordinator, other staff, including counselors and job coaches, also participated in the training workshop. The workshop covered a discussion of general knowledge of logic model components, with emphasis on the difference between outputs and outcomes, as this was one of the issues identified in the ECB readiness assessment. The program coordinator was familiar with the components of the United Way logic model but lacked a full understanding of the difference between outputs and outcomes, a common challenge for staff of community organizations (Kaplan \& Garrett, 2005). Following the workshop, the program coordinator expressed her desire to further develop her skills and the need to obtain more one-on-one technical assistance, from the university partners, to develop a logic model of the employment program that included specific, measurable, attainable, realistic and timely (SMART goals; Drucker, 1954) goals and clearly defined outcome indicators.

After the workshop and as part of an ongoing skill-building process, the university partners provided the program coordinator with one-on-one technical assistance using an 
interview process and the United Way logic model format (United Way of American, 1996). The technical assistance consisted of brainstorming sessions about the connection between the program’s goals and components, funders’ requirements, and the expected impact of the employment program on adults with ID. Using the United Way logic model, the university partners helped the program coordinator identify how key pieces of information were components of and could be included in a graphic logic model. The university partners emphasized differentiating outputs from outcomes; lining-up goals with activities, inputs, and outcomes; and identifying valid outcome indicators. The team identified several outcome indicators during the brainstorming sessions, such as the number of participants gaining employment and the length of participants' employment. To facilitate the development of the logic model and an understanding of its component parts, one of the university partners, the first author, acted as a “coach,” playing the roles of "facilitator” and "critical friend” (see Fetterman \& Wandersman, 2005).

Meetings between the university partners and the program coordinator consisted of an exchange of the program coordinator's knowledge of the program and the university partners' skills in incorporating that knowledge into an evaluation plan. As such, both university partners and the program coordinator shared their expertise in evaluation and program functioning, respectively, and learned from each other (see Alkin \& Christie, 2004; Fawcett et al., 2003).

Conducting an outcomes evaluation. Two goals that the program coordinator had established were to increase the number of participants placed in permanent jobs and to increase the efficiency of services provided to adults with ID. Pressure for accountability from senior managers and a desire to set realistic future goals based on past accomplishments led the program coordinator to decide to examine the program's outcomes. To do this, we agreed to 
analyze archival data from the five previous fiscal years on the employment history and employment status of all 30 program participants. Supported by ongoing technical assistance, the employment program coordinator framed the following evaluation questions for the outcomes evaluation: How many people with ID were recruited and placed in jobs in the last five fiscal years? How many hours of support are needed to secure employment? What types of jobs do participants obtain?

Participation in the different phases of the evaluation of the archival data allowed the program coordinator to improve her evaluation knowledge and skills. However, during the data entry and analysis phases of the evaluation, she indicated that she lacked the time to enter the data and lacked access to appropriate software to analyze the data. Therefore, the university partners completed the time-consuming task of data entry and the technical evaluation task of data analysis, but carefully explained and discussed the analyses with the program coordinator. As a result of these explanations and discussions, the university partners modified some of the analyses to better meet the employment program coordinator's information needs. As stated by Keener, Snell-Johns, Livet-Dye, and Wandersman (2005), participation of all stakeholders in every phase of the evaluation is often a challenge as it is difficult to create evaluation capacity teaching skills such as entering and analyzing data.

The program coordinator’s improved knowledge and skills helped her take ownership over the evaluation process. For example, during the interpretation of results phase, the program coordinator brought members of her staff into the group discussions so that they could interpret the results of the outcome evaluation, together with the university partners. The collaborative effort to analyze the results added depth to the interpretive process and helped to contextualize the significance of the information in relation to the evaluation questions. The program 
coordinator identified the types of employment and job settings as important outcomes to track in future evaluations since most of the employed participants had janitorial jobs at the CBO. An important goal for the program coordinator was to place participants in more skilled jobs outside of the organization within the community. These discussions also helped the program coordinator decide on the report outline and format for presenting the evaluation information to other stakeholders in the organization.

The program coordinator developed new insights into the uses of evaluation within her program and organization. The program coordinator and university partners wrote a comprehensive report that summarized the evaluation efforts, the results of the outcomes evaluation, and recommendations for improving the employment program services and the program's documentation system. The program coordinator presented the evaluation results to her staff and the CBO director. In the words of the program coordinator: "(The) report put on paper the situation. We are doing great with the resources that we have. And the report justifies more money. It also can help us access more staff later on.” The program coordinator's attitude towards the value and potential use of the report contrasted with her previous practices of using program reports only for billing and accountability purposes and not for program improvement. As she stated, “(in the past) I would count my numbers and put it in a binder for (the funder) when they come.”

In summary, the collaboration between the university and community partners focused on the implementation of ECB activities to develop a program logic model as the basis for conducting an outcomes evaluation. After developing an increased awareness of the need for evaluation and motivation to mainstream evaluation practices in the employment program, the 
program coordinator developed a parallel process with her staff. As such, her role at the organization became that of a catalyst-for-change.

\section{The Role of the Catalyst}

The second purpose of this article is to describe the role of the program coordinator as a catalyst-for-change within the organization. Specifically, the program coordinator played a key role in serving as a catalyst by diffusing evaluation knowledge and skills to her staff and promoting mainstreaming and use of evaluation practices within the organization.

Diffusing evaluation knowledge and skills. To diffuse evaluation knowledge and skills, the program coordinator engaged in a process of obtaining buy-in from her staff in several key aspects of evaluation. This process included transferring her knowledge on developing logic models and SMART goals to other staff (Drucker, 1954), modeling how to identify evaluation questions and outcomes, and making staff aware of the need for evaluating program outcomes.

The program coordinator worked with members of her staff on refining the logic model that she had developed with the university partners. She used her knowledge and skills to teach other staff about outputs and outcomes and the difference between these components. A demonstration of the catalyst process was apparent when the program coordinator shared with university partners the program logic model that she had displayed on her office wall, very proudly. She had used post-it paper to define and discuss the different goals, inputs, outputs, and outcomes of the employment program with a member of her staff. As articulated by the program coordinator, “The illustrative format helped me and the staff understand the relationship between our day-to-day activities and the overall goals of the employment program.” As a result of the outcome evaluation that we conducted, the program coordinator developed evaluation knowledge and skills to frame evaluation questions, develop an evaluation plan, identify 
information and methods to answer the evaluation questions, interpret her findings, and write a comprehensive evaluation report.

Involvement of program staff members at different points in the various phases of the evaluation was critical to the catalyst process. For example, the program coordinator discussed the evaluation questions with one member of her staff and together they identified relevant evaluation questions for the program. Other members of her staff participated by retrieving and entering incomplete data into the database to complete the evaluation. The program coordinator also shared the results of the data analysis with her staff and together they interpreted the findings. She involved every member of her staff in writing the report and providing feedback on the final recommendations. Through a parallel process, the program coordinator transferred evaluation knowledge and skills by having brainstorming sessions with her staff and providing ongoing feedback to them on their input related to evaluation plans and logic models.

Diffusing evaluation knowledge and skills was coupled with building an increased awareness of the need for evaluation to improve the program outcomes. The program coordinator was also a catalyst-for-change by making the staff aware of the need for evaluation. She pointed out to her staff how the results of the outcomes evaluation provided evidence of the program's need for additional staff. As she shared with the university partners:

We are (now) comparing the number of hours worked with the number of hours billed, across customers... Before we just couldn’t do it... Now I can see (the relationship) and (the staff and senior managers) can see it. Now it justifies the need for more job coaches. Promoting mainstreaming and use of evaluation practices. The program coordinator was able to work with her staff and staff from other programs within the organization to get them to buy into evaluation practices. As such, she talked to staff about the importance of 
documenting the impact of their programs, shared what she was doing in the employment program with staff in other departments of the organization and provided them with feedback on logic models. This contributed to changes in the learning climate of the organization regarding evaluation and opened the doors for staff to learn from one another and provide each other feedback, forming a community of learners (see Fetterman \& Wandersman, 2005).

The need for evaluation of the employment program was urgent, based on demands from senior managers and funders. This need bolstered the efforts of the program coordinator in encouraging her staff to engage in evaluation practices. With the program coordinator's support, staff became more involved in evaluation planning and evaluation activities, and developed more ownership over the development, evaluation, and improvement of the program. Specifically, all staff began to meet regularly to talk about the evaluation of the program and its findings. These meetings gave staff an opportunity to learn about evaluation and provide feedback about the program. According to the program coordinator:

If the staff feels disconnected, they don't see the whole picture. They don't know where the program is going. Once they buy into it they say, 'I will take leadership of this piece.' And different staff took ownership of different parts of the program.

\section{The Assessment of ECB Outcomes}

The third purpose of this article is to describe the outcomes that resulted from this ECB effort. As noted by researchers and practitioners alike, it is critical to assess ECB outcomes, including mainstreaming and use of evaluation skills (Duignan, 2003; Kapucu et al., 2007; Sobeck \& Agius, 2007).

As noted above, we used direct observation, document reviews, and entry and exit interviews with the program coordinator to assess the outcomes of the ECB catalyst approach. 
We used the three data sources to examine outcomes related to evaluation knowledge and skills, referred to as individual factors including cognitive, behavioral, and affective components (Taut, 2007); and mainstreaming and use of evaluation results, referred to as organizational factors (Naccarella et al., 2007; see Table 2 for a summary of the ECB outcomes).

Outcomes related to evaluation knowledge and skills. According to Taut (2007), evaluation skills and knowledge can be assessed by examining individual cognitive, affective, and behavioral aspects of ECB. Cognitive indicators of ECB include evaluation knowledge and evaluative thinking that are incorporated into professional practice (Taut, 2007). At the end of the collaboration, the employment program coordinator stated in the interview that she had increased knowledge of the evaluation process allowing her to examine the progress of the employment program as well as the progress of other programs in which she was partially involved. We validated her perceptions with other methods. In the document review, we analyzed the most recent version of the employment program logic model observing that the logic model included all the components that United Way requires and that the components related to one another in a sequence of if-then relationships. Specifically, the outcomes were aligned with one or more outputs showing a clear understanding of the relationships between them. In addition, during the interview, the program coordinator rated herself very highly on skills to conduct evaluation and alluded strongly to knowing what she was doing. As an example of her evaluative thinking she stated, "I am trying to do innovative things and use our information in innovative ways. For the job readiness program, I picked a curriculum... (Two staff members) are tracking all of this, to see how it works.” This indication of ongoing use of evaluation was central to new developments in the employment program. 
Behavioral indicators refer to improved skills to integrate evaluation into everyday work and the programming cycle (Taut, 2007). The program coordinator gained evaluation skills that allowed her to differentiate between outputs and outcomes and to explain their differences to staff, a challenge she identified at the beginning of the collaboration. These new skills led her to focus on other relevant outcomes for the program participants, such as participants' contributions to the community. According to the program coordinator, "Before, we used to get trapped in the reporting of outputs and not knowing if the program participants felt more independent, if they felt they were contributing to the community.”

Learning evaluation skills also helped the program coordinator take control and ownership over the process of developing a logic model that best reflected the program goals. As such, the program coordinator was able to develop new evaluation questions, identify appropriate methods to answer these questions, and incorporate both the new questions and methods into revisions of the program’s logic model. According to the program coordinator, before the partnership began, staff often proposed methods of collecting information from participants without questioning what the purpose of the method was and what information would be collected. For example, the program coordinator had recurrently used focus groups to explore program issues because she had experience with this method. This ECB experience helped her to learn about other evaluation methods such as the use of surveys, the analysis of archival data, and to think more critically and make informed decisions about the best method to collect needed information.

Affective indicators that result from the ECB are positive attitudes towards evaluation, increases in ownership of the evaluation process, and increases in motivation to engage in evaluation (Taut, 2007). At the end of the collaboration, the program coordinator stated: 
[Evaluation] gives you a clear idea of what is expected, for you and for your program. That is shared with staff. Everyone is working on the same goal. You understand the relationship of what you do to the goal. You are able to show other staff, administrators, what you are doing. In the past, I had a hard time showing others. It was hard for them to understand our programs.

She also stated:

Discussion and a call for active participation are very important. It is critical that there is a discussion (of the findings) rather than a presentation. Throughout the whole collaboration process I felt I was the one deciding- how do I see the program, how do I want the program to be.

Regarding ownership of the evaluation, the program coordinator stated that the ECB process “helped me see that I can use [evaluation] to justify what is needed.” Regarding motivation to engage in evaluation, she said:

I am very motivated. It is important to do it. Keeps you on track. Although it is time consuming, if you do it routinely, people expect to be able to review it .... That's a good thing.

Outcomes related to mainstreaming and using results. The program coordinator and her staff used the results of the outcome evaluation in several ways: They set realistic data-driven goals for the employment program for the subsequent fiscal year; they applied for funding to hire a new job developer; and began a brainstorming process to improve program services and documentation systems. Based on the results of the evaluation, staff decided to work on developing and institutionalizing a job-readiness program for adults with ID. Other changes included assigning two staff members to take responsibility for the impact evaluation of the 
program. To improve the documentation of program activities, the program coordinator assigned two other staff members to regularly monitor the program staff's efficiency in providing supports. This, in turn, led the employment program staff to mainstream evaluation practices into their daily job activities. As the program coordinator stated:

We have a different framework, a different way of seeing things. There is little resistance from the staff. We have three new programs. In one of them we have 40 new people. We have met our numbers for the first time in two years. We were not billing correctly. Now that everybody is part of the process we can compare the hours job coaches spend with the participants with the hours the clients work. We have modified the reports and every staff reports progress monthly.

\section{Discussion}

This case study illustrated the process of building evaluation capacity in one staff person in an employment program that provides services to people with ID. The program coordinator demonstrated evaluation capacity at Taut's (2007) cognitive, behavioral, and affective levels. Evaluation knowledge, skills, and awareness of the benefits of using evaluation findings changed the program coordinator's values regarding evaluation. These developments, in turn, allowed her to progress from documenting program outputs solely to satisfy funders' demands to using the findings of an outcomes evaluation to improve the program. Prior to this ECB partnership, the program coordinator regarded evaluation as something disassociated from program goals and community needs. The ECB process also prepared her to be an effective catalyst for change who could diffuse evaluation knowledge and skills to other staff and promote mainstreaming and use of evaluation results within the program. The process of partnering with the university team to develop a program logic model and conduct an outcomes evaluation facilitated a unified 
conceptualization of the program. As the partnership unfolded, program staff gained an integrated vision of evaluation as a tool and as a process to improve their program and better support adults with ID to obtain and maintain employment.

Given the current economic situation that CBOs are facing, many may not be able to commit more than one staff person to ECB efforts (Carman 2007; Kapucu et al., 2007). This case study highlights the ECB process on one staff person, who in turn acts as a catalyst, influencing ECB outcomes at individual and organizational levels. However, a catalyst's approach is not without caveats and limitations. The following are critical considerations in adopting the catalyst approach.

First, the importance of identifying a person with leadership responsibilities within the $\mathrm{CBO}$ as the potential catalyst cannot be underestimated. A leader has power to allocate the resources that are likely to change the organization's culture and infrastructure in terms of evaluation (Hoole \& Patterson, 2008). The power to change an organizations’ practices, regarding evaluation, might be limited if the staff serving as catalyst has no access to resources, no easy access to the leadership, or few decision-making privileges. The program coordinator had supervisory responsibilities over other staff in the employment program, was responsible for the program's budget, was responsible for reporting on program outputs and outcomes, and had the power to make changes within the program. Without these responsibilities, the program coordinator would not have had opportunities or the power to make learning related to evaluation a part of program meetings or to engage staff in the process of interpreting the findings of the outcomes evaluation. In other words, without these responsibilities, the catalyst would not have had opportunities to prioritize learning related to evaluation or to influence other staff to consider 
new ways of thinking about the program’s goals, operations, documentation practices, and outcomes.

Second, the staff member who is the focus of the capacity building effort must be committed to diffusing evaluation skills and knowledge to other staff. Given the high staff turnover in many CBOs (Carman, 2007; Carman \& Fredericks, 2010), it is critical that the catalyst be selected carefully to maximize the likelihood that his or her tenure allows for evaluation capacity to be developed within the organization. In this case study, the program coordinator had been employed at the CBO for 11 years when the ECB collaboration began and was committed to the ECB effort. If the catalyst leaves the organization before he or she is able to transfer knowledge and skills to other staff members, the ECB effort is unlikely to succeed. This is, without doubt, one of the risks of using a one-person catalyst approach.

Third, the staff member serving as the catalyst needs to be provided with support from other administrators and leaders to address resistance and lack of buy-in from staff. Change does not come easily within nonprofit organizations. Currently, CBOs struggle with staffing issues, broader management issues, and lack of resources. Therefore, asking staff to change how they do things might be perceived as requiring more work (Carman \& Fredericks, 2010). In this case study, the program coordinator counted with the unconditional support of the organization's upper administration. This was the case, in part, because of the CBO’s long history of collaboration with the university partners and their high regard for all previous collaborations.

The use of a collaborative immersion approach (see Huffman, 2008) and ECB strategies such as brainstorming and training sessions (see Preskill \& Boyle, 2008) supported the transfer of learning between the university partners and the program coordinator, as well as between the program coordinator and her staff. The participatory nature of both approaches allowed for the 
ECB process to develop according to the specific needs of the program and at a pace that was appropriate for the program coordinator and her staff. As such, the program coordinator diffused her learning at times and during activities that occurred naturally during program routines (i.e., staff meetings) and were therefore relevant for her and her staff. The employment program staff became aware of the need for evaluation and motivated to participate in evaluating their program. This ECB participatory process also set the stage for the gradual mainstreaming and use of evaluation practices within the employment program.

Measuring the outcomes of ECB efforts is a new area of research in need of additional development (Preskill \& Boyle, 2008). In an attempt to advance the ECB outcomes literature, we measured the program coordinator's development and diffusion of knowledge and skills, mainstreaming, and use of evaluation practices (Suarez-Balcazar et al., 2010). Measuring these outcomes also represents an important development for ECB research on this novel catalyst approach. Moreover, these reported results provide evidence of the usefulness of Taut's outcomes framework (2007) related to cognitive, behavioral, and affective outcomes for this catalyst approach, as noted above.

Taken together, analysis of this case study reveals several important findings. The findings suggest that the development of a logic model and engagement in an outcomes evaluation are complementary processes that lead to authentic learning. The program coordinator reported that she found developing the logic model in collaboration with the university partners to be very useful. She contrasted this experience with prior experiences with other evaluators at one-day trainings, after which she had no opportunity for follow-up contact or ongoing consultation to have her questions answered or her learning consolidated. In this case study, she 
noted the usefulness of varied forms of support in conjunction with being able to use evaluation concepts and techniques as an organizational development tool.

In terms of ECB outcomes, the university team observed that the program coordinator was also able to accurately develop and describe her program logic model and teach her staff to use it. By teaching others, she demonstrated her evaluation knowledge and skills as well as her ownership of the evaluation process. Further, the logic models that the program coordinator developed were central in helping her, and her staff, form a vision for linking program operations with evaluation operations and for linking the results of the outcomes evaluation with realistic future goals for the program.

\section{Strengths of the Study}

This case study has two main strengths that are worthy of note. First, the case study describes a novel approach. This is a potential solution to the challenge that many CBOs face in engaging in ECB efforts due to the lack of staff and time to engage in an ECB process with external evaluators. Involving one staff member in the ECB process with the evaluators (in this study the university partners) respected the regular operations of the program by allowing the other staff members to continue their daily routines. The catalyst, in her leadership position, was able to identify when and how to transfer her evaluation capacity to other members of the staff. Second, the case study differentiates between the ECB process, the role of the catalyst, and the outcomes resulting from the process. The case study highlights individual outcomes, such as evaluation knowledge and skills, and organizational outcomes, such as mainstreaming and use of evaluation findings. In this way, the current study both supports and advances past research related to ECB processes and outcomes.

\section{Limitations of the Study}


This case study has two main limitations. First, the interview data included the views of only one individual. Although the current study used multiple sources of data to analyze the ECB process and its outcomes, we only conducted interviews with the program coordinator; we did not assess the perspectives of her staff or others within the organization who were stakeholders in the process (i.e., senior managers). Gathering other perspectives might reveal nuance and variability in the perceptions of the ECB process at the CBO. The second limitation is that we measured the ECB process and its outcomes during and immediately after the end of the partnership. As such, this case study did not assess whether and how evaluation capacity is continually developed, sustained, and used within organizations. Therefore, we cannot make claims about the sustainability of the evaluation process or outcomes that we observed.

\section{Recommendations}

Based on our experiences in implementing this case study, we have identified several recommendations. These recommendations are intended for evaluators who develop evaluation capacity within nonprofit organizations, researchers who study ECB processes and outcomes, and funders who seek to build evaluation capacity within CBOs.

Recommendations for evaluators. Evaluators who are engaging in ECB work should consider working with one staff member within organizations when lacking the economic and human resources to engage in a more traditional and full-blown ECB effort. Given the importance of the organizational infrastructure for the development of evaluation capacity, this staff member should be in a leadership position, be willing to be a catalyst for ECB in the organization, and be committed to the organization and to diffusing evaluation capacity within the organization. Another important area for evaluators is to examine the impact of the capacity building process on the growth and professional development of the staff serving in the role of 
catalyst for change (i.e., to what degree does acquiring evaluation skills facilitate the promotion of staff within and outside the organization?).

Recommendations for researchers. Researchers who seek to increase our understanding of the ECB process and its outcomes should consider conducting research on a catalyst-forchange approach to ECB. In doing so, researchers should consider gathering the perspectives of multiple staff members regarding the ECB process and its outcomes, including the perspectives of the catalyst, of staff that are the target of the catalyst's efforts, and of other stakeholders in the process, including senior managers and funders. These multiple perspectives would provide a more comprehensive account of the process, outcomes, and contexts that are related to using a catalyst approach to ECB. In addition, future ECB studies should include follow-up measures, collected at different points in time, to assess whether and how evaluation capacity is developed, sustained, and used. Such research could more fully inform our understanding of the organizational change process that is related to ECB.

Recommendations for funders. Program funders who seek to improve the evaluation quality of the programs they are funding should consider supporting and assessing the efficacy of catalyst approaches to ECB. Specifically, funders such as United Way often require that program personnel participate in evaluation training and submit logic models of their programs as part of their applications for funding. In this case study, we used multiple methods to achieve the outcomes reported. Moreover, the program coordinator noted that these methods contributed to her learning and ability to diffuse evaluation practices throughout the organization. As such, funders might consider long-term commitment to building evaluation capacity and to using methods described in this study, such as immersion approaches, brainstorming meetings, technical assistance, and coaching/mentoring, in addition to training. 


\section{Conclusion}

This case study reports a novel approach to creating evaluation capacity within one CBO. Study findings indicate that a catalyst-for-change approach to ECB may be useful for organizations that could benefit from increased evaluation capacity but are challenged with limited staff. Use of accepted ECB processes with one staff member of a CBO led to diffusion of evaluation knowledge and skills and promotion of mainstreaming and use of evaluation practices within the organization. 


\section{References}

Alkin, M.C. \& Christie, C.A. (2004). An Evaluation Theory Tree. In M. Alkin (Ed.), Evaluation Roots: Tracing Theorists Views and Influences (12-65). Thousand Oaks, California: Sage Publications, Inc.

Arnold, M. E. (2006). Developing evaluation capacity in extension 4-H field faculty. American Journal of Evaluation, 27(2), 257-269. doi:10.1177/1098214006287989

Baizerman, M., Compton, D., \& Stockdill, S.C. (2002). New Directions for ECB. New Directions for Evaluation, 93, 109-120. Retrieved from http:/www3.interscience.wiley.com/cgi-bin/fulltext/92013256/PDFSTART

Behrens, T. R., \& Kelly, T. (2008). Paying the piper: Foundation evaluation capacity calls the tune. In J. G. Carman \& K. A. Fredericks (Eds.). Nonprofits and Evaluation. New Directions for Evaluation, 119, 35-70. Retrieved from http://www3.interscience.wiley.com/journal/121397489/issue

Carman, J. (2007). Evaluation practice among CBOs. American Journal of Evaluation, 28(1), 60-75. doi:10.1177/1098214006296245

Carman, J.C. \& Fredericks, K.A. (Eds) (2008). Nonprofits and evaluation. Empirical evidence from the field. In J. G. Carman \& K. A. Fredericks (Eds.), Nonprofits and evaluation. New Directions for Evaluation, 119, 51-71. Retrieved from http://www3.interscience.wiley.com/cgi-bin/fulltext/121397495/PDFSTART

Compton, D., Baizerman, M., Preskill, H., Rieker, P., \& Miner, K. (2001). Developing evaluation capacity while improving evaluation training in public health: The American Cancer Society's Collaborative Evaluation Fellows Project. Evaluation and Program 
Planning, 24(1), 33-40. Retrieved from

http://www.sciencedirect.com/science/journal/01497189

Compton, D., Baizerman, M., \& Stockdill, S. (2002). Special Issue: The Art, Craft, and Science of Evaluation Capacity Building. New Directions for Evaluation, 93, 1-120. Retrieved from http://www.eval.org/Publications/NDE.asp

Compton, D. W., Glover-Kudon, R., Smith, I.E., \& Avery, E. (2002). Ongoing capacity building in the American Cancer Society (ACS) 1995-2001. In D.W. Compton, M. Baizerman, \& S.H. Stockdill (Eds.), The Art, Craft, and Science of Evaluation Capacity Building. New Directions for Evaluation, 93 (pp.47-61). San Francisco, CA: Jossey-Bass. Retrieved from http://www.eric.ed.gov/

Connolly, P. \& York, P. (2002). Evaluating Capacity-Building Efforts for Nonprofit Organizations. OD Practitioner, 34(4), 33-39. Retrieved from http://www.tccgrp.com/pdfs/per_art_evaluating.pdf

Cousins, J. B., Goh, S. C., Eliott, C. \& Aubry, T. (May, 2008). Government and voluntary sector differences in organizational capacity to do and use evaluation. Presented at the annual meeting of the Canadian Evaluation Society, Québec. Retrieved from http://evaluationcanada.ca/site.cgi?s=1

Drucker, P. F. (1954). The Practice of Management. HarperCollins Publishers: New York, NY.

Duignan, P. (2003). Mainstreaming Evaluation or Building Evaluation Capability? Three Key Elements. New Directions for Evaluation, 99, 7-21. Retrieved from http://www3.interscience.wiley.com/journal/105561513/abstract

Fawcett, S. B., Boothroyd, R., Schultz, J.A., Francisco, V.T., Carson, V., \& Bremby, R. (2003). Building capacity for participatory evaluation within community initiatives. In Y. Suarez- 
Balcazar \& G. W. Harper (Eds.), Empowerment \& participatory evaluation of community interventions: Multiple benefits (pp. 21-36). New York: The Haworth Press. Retrieved from http://www.informaworld.com/smpp/content content=a903437371\&db=all

Fetterman, D. M. \& Wandersman, A. (2005). Empowerment evaluation principles in practice. New York: Guilford Publications.

Gibbs, D., Napp, D., Jolly, D., Westover, B., \& Uhl, G. (2002). Increasing evaluation capacity within community-based HIV prevention programs. Evaluation and program Planning. 25(3), 261-269. Retrieved from http://www.sciencedirect.com/science?

Gugiu, P. C. \& Rodriguez-Campos, L. (2007). Semi-structured interview protocol for constructing logic models. Evaluation and Program Planning, 30(4), 339-350. Retrieved from http://www.sciencedirect.com/science?

Hendricks, M. \& Handley, E. (1990). Improving the recommendations from evaluation studies. Evaluation and Program Planning, 13(2), 109-117.

Hendricks, M., Plantz, M. C. \& Pritchard, K. J. (2008). Measuring outcomes of United Wayfunded programs: Expectations and reality. In J. G. Carman \& K. A. Fredericks (Eds.). Nonprofits and Evaluation. New Directions for Evaluation, 119, 13-35.

Hoole, E. \& Patterson, T.E. (2008). Voices from the field: Evaluation as part of a learning culture. In J.G. Carman \& K.A. Fredericks (Eds), Nonprofits and evaluation. New Directions for Evaluation, 119, 93-113. Retrieved from http://www3.interscience.wiley.com/journal/121397500/abstract

Huffman, D., Thomas, K., \& Lawrenz, F. (2008). A Collaborative Immersion Approach to Evaluation Capacity Building. American Journal of Evaluation, 29(3), 358-368. doi: $10.1177 / 1098214008318798$ 
Kaplan, S. A. \& Garrett, K. E. (2005). The use of logic models by community-based initiatives. Evaluation and Program Planning, 28(2), 167-172. Retrieved from http://www.sciencedirect.com/science?

Kapucu, N., Augustin, M., \& Krause, M. (2007). Capacity Building for Community-Based Small Nonprofit Minority Health Agencies in Central Florida. The International Journal of Volunteer Administration, 24(3), 10-17. Retrieved from http://www.ijova.org/PastIssues/xxiv_3.htm

Keener, D., Snell-Johns, J., Livet-Dye, M., \& Wandersman, A. (2005). Lessons that influenced the current conceptualization of empowerment evaluation: Reflections from two evaluation projects. In D. M. Fetterman \& A. Wandersman (Eds.), Empowerment evaluation: Principles in Practice (pp. 73-91). New York: Guilford Press.

King, J.A. (2002). Building the Evaluation Capacity of a School District. New Directions for Evaluation, 93, 63-79. Retrieved from http://www3.interscience.wiley.com/cgibin/fulltext/92013254/PDFSTART

Mackay, K. (2002). The World Bank’s ECB Experience. New Directions for Evaluation. 93, 81100. Retrieved from http://www3.interscience.wiley.com/cgi-bin/fulltext/ 92013252/PDFSTART

Merriam, S.B., Caffarella, R.S. \& Baumgartner, L.M. (2007). Learning in adulthood: A comprehensive guide ( $3^{\text {rd }}$ Ed.). San Francisco: Jossey-Bass.

Milstein, B., Chapel, T.J., Wetterhall, S. F., \& Cotton, D.A. (2002). Building Capacity for Program Evaluation at the Centers for Disease Control and Prevention. New Directions for Evaluation, 93, 27-46. Retrieved from http://www3.interscience.wiley.com/cgibin/fulltext/92013258/PDFSTART 
Naccarella, L., Pirkis, J., Kohn, F., Morley, B., Burgess, P., \& Blashki, G. (2007).

Building evaluation capacity: Definitional and practical implications for an Australian case study. Evaluation and Program Planning, 30(3), 231-236. Retrieved from http://www.sciencedirect.com/science?

Preskill, H. \& Boyle, S. (2008). A Multidisciplinary Model of Evaluation Capacity Building. American Journal of Evaluation, 29(4), 443-459. doi:10.1177/1098214008324182

Sobeck, J. \& Agius, E. (2007). Organizational capacity building: Addressing a research and practice gap. Evaluation and Program Planning, 30, 237-246. Retrieved from http://www.sciencedirect.com/science?

Stevenson, J. F., Florin, P., Mills, D. S., \& Andrade, M. (2002). Building evaluation capacity in human service organizations: A case study. Evaluation and Program Planning, 25(3), 233-243. Retrieved from http://www3.interscience.wiley.com/cgibin/fulltext/92013258/PDFSTART

Stockdill, S., Baizerman, M., \& Compton, D. (2002). Toward a definition of the ECB process: A conversation with the ECB literature. New Directions for Evaluation, 93, 1-25. 233-243. Retrieved from http://www3.interscience.wiley.com/cgi-bin/fulltext/ 92013257/PDFSTART

Suarez-Balcazar, Y., Taylor-Ritzler, T., Garcia-Iriarte, E., Keys, C. B., Kinney, L., Ruch-Ross, H., Leung, P., Restrepo-Toro, M., \& Curtin, G. (2010). Evaluation capacity building: A culturally- and contextually-grounded interactive framework and exemplar (in Balcazar, Suarez-Balcazar, Taylor-Ritzler \& Keys, Eds.), Race, culture and disability: Rehabilitation science and practice. Boston, MA: Jones and Bartlett. 
Taut, S. (2007). Studying self-evaluation capacity building in a large international development organization. American Journal of Evaluation, 28(1), 45-59. doi:10.1177/1098214006296430

Trevisan, M. (2002). Evaluation capacity in K-12 school counseling programs. American Journal of Evaluation, 23(3), 291-305. doi:10.1177/109821400202300305

United Way of America (1996). Outcome and measurement resource network. Retrieved from http://www.liveunited.org

Valery, R. \& Shakir, S. (2005). Evaluation capacity building and humanitarian organization. Journal of Multidisciplinary Evaluation, 3, 87-112. Retrieved from http://preval.org/documentos/2205.pdf\#page=87 
Table 1. Catalyst-for-change approach to ECB process

\begin{tabular}{ll}
\hline \multicolumn{1}{c}{ Purpose } & \multicolumn{1}{c}{ Approach/Strategies } \\
\hline $\begin{array}{l}\text { Planning and designing the } \\
\text { ECB process }\end{array}$ & \\
\hline ECB readiness assessment & $\begin{array}{l}\text { Brainstorming sessions } \\
\text { Open-ended interview } \\
\text { Review of reports }\end{array}$ \\
\hline $\begin{array}{ll}\text { ECB objectives: } \\
\text { developing a logic model } \\
\text { as a tool for planning and } \\
\text { implementing an } \\
\text { conaluation } \\
\text { evaluation }\end{array}$ & Review of the ECB readiness assessment results \\
\hline ECB process and activities & $\begin{array}{l}\text { Collaborative immersion approach (Huffman et al., 2008) } \\
\text { ECB teaching strategies (Preskill \& Boyle, 2008) }\end{array}$ \\
\hline Developing a logic model & Training workshop \\
& One-on-one technical assistance \\
\hline $\begin{array}{l}\text { Conducting an outcomes } \\
\text { evaluation }\end{array}$ & $\begin{array}{l}\text { Analysis of archival data } \\
\text { Ongoing consultation }\end{array}$ \\
\hline
\end{tabular}


Table 2. Outcomes of a Catalyst-for-change approach to ECB

\begin{tabular}{|c|c|}
\hline & Catalyst and her staff \\
\hline \multicolumn{2}{|l|}{ Knowledge \& skills } \\
\hline Cognitive & $\begin{array}{ll}\text { - } & \text { Knowledge of evaluation concepts } \\
\text { - } & \text { Evaluative thinking }\end{array}$ \\
\hline Behavioral & $\begin{array}{l}\text { - Use of evaluation skills, logic models, and evaluative } \\
\text { thinking }\end{array}$ \\
\hline Affective & $\begin{array}{l}\text { - } \text { Positive attitudes towards evaluation } \\
\text { - } \quad \text { Motivation to engage in evaluation } \\
\text { - Ownership over evaluation }\end{array}$ \\
\hline $\begin{array}{l}\text { Mainstreaming \& use of } \\
\text { evaluation results }\end{array}$ & $\begin{array}{l}\text { - } \quad \text { Setting goals for the employment program } \\
\text { - } \quad \text { Funding application } \\
\text { - } \quad \text { Brainstorming process for program services and } \\
\text { - } \text { documentation improvement } \\
\text { - } \quad \text { Staff assignment to regular evaluation tasks, including } \\
\text { monitoring evaluation outcomes and the program staff's } \\
\text { efficiency }\end{array}$ \\
\hline
\end{tabular}

